\title{
Association of Prepregnancy Nutritional Status and Physical Activity Levels with Birth Size Outcomes among West Sumatran Pregnant Women: Results from the Vitamin D Pregnant Mothers Cohort Study in Indonesia
}

\author{
Arif Sabta Aji ${ }^{12 *}\left(\mathbb{D}\right.$, Yusrawati Yusrawati ${ }^{3}$, Safarina G. Malik ${ }^{4}$ (D), Chahya Kusuma ${ }^{2}$, Nurindrawaty Lipoeto ${ }^{5}$ (D) \\ ${ }^{1}$ Department of Nutrition, Faculty of Health Sciences, Universitas Alma Ata, Yogyakarta, Indonesia; ${ }^{2}$ Department of Public \\ Health, Alma Ata Graduate School of Public Health, Faculty of Health Sciences, Universitas Alma Ata, Yogyakarta, Indonesia; \\ ${ }^{3}$ Department of Obstetry and Gynaecology, Faculty of Medicine, Universitas Andalas, Padang, Indonesia; ${ }^{4}$ Department of \\ Eijkman, Institute for Molecular Biology, Jakarta, Indonesia; ${ }^{5}$ Department of Nutrition, Faculty of Medicine, Andalas University, \\ Padang, Indonesia
}

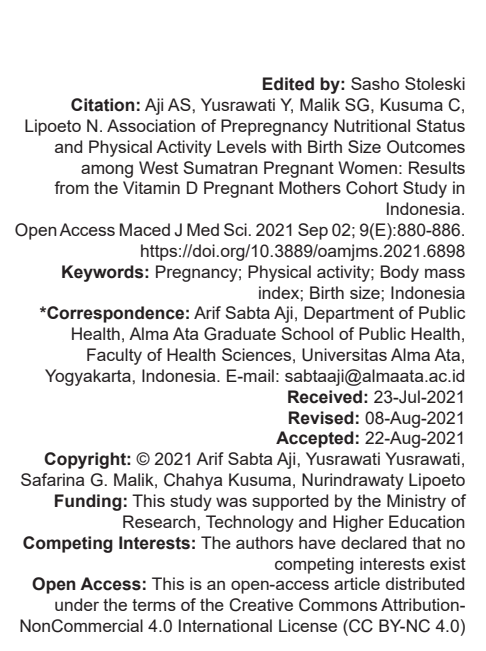

\section{Introduction}

Views on physical activity during pregnancy have taken on new meanings and implications throughout past decades. This has created a move towards standardization of the prenatal physical activity level (PAL) recommendations [1]. Nevertheless, the prevalence of PAL during pregnancy is low among the pregnant women population worldwide [1], [2]. Moderate PAL intensity is suggested to be a recommended lifestyle for women in reproductive age to mediate the weight maintenance and weight gain during the pregnancy. It is classified to have beneficial effects on reducing maternal complication risks related to fetal growth and development and the occurrence of chronic diseases in children later in life. Several factors, indirect or direct, have been reported to have a relationship with fetal development such as socio-economic status, nutritional status, blood pressure, gestational diabetes mellitus, smoking habit, unhealthy lifestyle, and prenatal care [3], [4]. Therefore, optimum weight gain, proper $\mathrm{PAL}$, and adequate requirements of nutrient intakes are the ideal characteristics of healthy lifestyle during pregnancy [5], [6].

Engaging maternal healthy and active behaviors during pregnancy may become useful for constricting excessive weight gain, improving obstetrical outcomes, and promoting optimal fetal growth trajectories [7]. However, the relationship between PAL during gestation and pregnancy outcomes in Indonesian women was poorly understood. Limited studies have investigated the association between maternal PAL and birth size outcomes, especially before and during pregnancy in Indonesian women. 
Therefore, the purpose of this study was to investigate the association between maternal physical activity status and birth size outcomes (birth weight, birth length, and head circumferences), and whether other determinants of confounding variables such as prepregnancy body mass index (PP-BMI) affect birth size outcomes.

\section{Methods}

\section{Research design and study subjects}

This study was a part of West Sumatran Vitamin D Pregnant Mothers (VDPM) cohort study which was observing pregnant mothers from the first trimester till to be delivered and we assess whether mother's Vitamin D status, gestational weight gain (GWG), physical activity, Vitamin D-related genes polymorphisms, dietary pattern, and other biochemical factors could determine mothers health, fetal growth and development, newborn anthropometry measurement, and other pregnancy indicators. The VDPM cohort study conducted at public health centers in five different cities (Padang, Padang Pariaman, Pariaman, Lima Puluh Kota, and Payakumbuh) in West Sumatra, Indonesia. The part of the cohort study has been published elsewhere, recently [3], [8], [9]. A total of 183 singleton pregnant women were recruited and had been followed up till birth. Data collection of the study conducted from June 2017 to March 2018.

Theinclusioncriteriaincluded:(1)Pregnantwomen that visited public health care in each site, (2) pregnancy in the first trimester (<13 weeks), (3) healthy based on the results of doctor's examination, and (4) willing to participate in the research by signing informed consent and followed the research procedure. Moreover, we excluded those who have a stillbirth, abortion, birth defects, pre-eclampsia, severe anemia, hypothyroidism, suffering chronic disease (diabetes mellitus, hypertension, abnormal heart function, and glandular thyroid disease), and multiple gestations. All participants were followed from the first trimester to deliveries process to assess birth size outcomes, such as birth weight, birth length, and head circumferences. After followed up process, we obtained 183 of available mother-infant pairs (Figure 1). This study protocol was conducted in accordance with the declaration of Helsinki and approved by the Ethics Committees on November 1, 2016 (No. 262/KEP/FK/2016). All women gave written informed consent and anonymity subject's data form for themselves before data collection and recruitment in this study.

\section{Socio-demographic and anthropometric of study participants}

We collected information such as age, parity, education, occupation, socioeconomic status, and

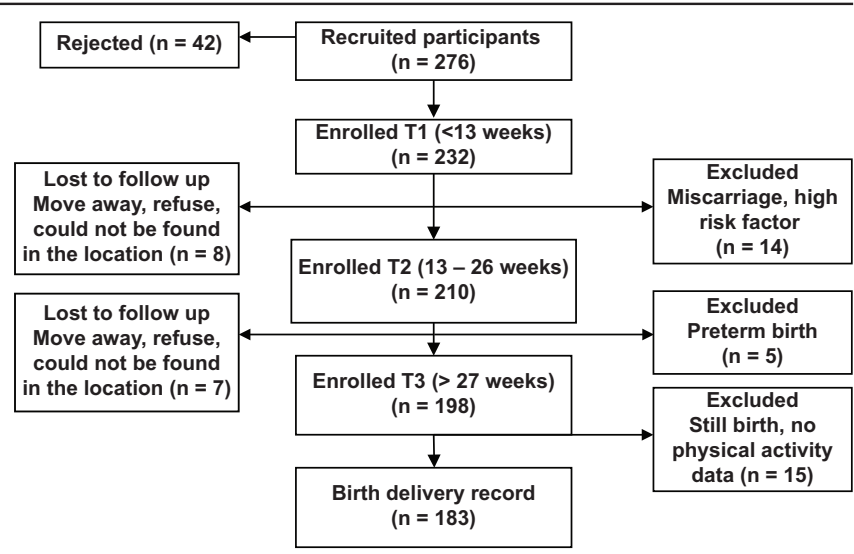

Figure 1: Vitamin D pregnant mothers cohort study participants diagram

geographical status of their living (urban or rural areas) at the enrollment process. At the first (T1), second (T2), and third trimester (T3), a trained research assistant (registered nutritionists) collected data of maternal anthropometry.

Bodyweight was measured to the nearest $100 \mathrm{~g}$ using an electronic scale (Seca 803, Seca $\mathrm{GmbH}$. Co. kg, Hamburg, Germany) and height was measured to the nearest millimeter using a stadiometer (OneMed Medicom stature meter, YF.05.05.V.A.1022, Indonesia). The BMI was estimated as weight $(\mathrm{kg})$ divided by the square of body height (m). PP-BMI was classified according to the World Health Organization (WHO) guidelines for Asian Population (underweight, $<18.5 \mathrm{~kg} / \mathrm{m}^{2}$; normal, 23.5-24.99 kg/m²; overweight, $25-29.99 \mathrm{~kg} / \mathrm{m}^{2}$; obese, $\geq 30 \mathrm{~kg} / \mathrm{m}^{2}$ ) [10]. The mid-upper arm circumferences (MUAC) $(\mathrm{cm})$ was measured using a MUAC tape measure (Medline-OneMed Medicom, Jakarta, Indonesia) midpoint between the elbow and the shoulder (acromion and olecranon) and place the tape around the left arm (the arm should be relaxed and hang down of the side of the body).

\section{PAL measurement}

"The Global Physical Activity Questionnaire" (GPAQ), developed by the WHO was used to measure physical activity [11]. The total time in moderate-tovigorous physical activity was calculated according to the WHO STEPwise method and was expressed as Metabolic Equivalent minutes per day (MET min/ day). Furthermore, women who have MET min/day more than equal to $600 \mathrm{MET} \mathrm{min} /$ day were classified as "active," and <600 MET min/week were classified as "inactive." Sedentary behavior (SB, min/day) was determined from the last question of the GPAQ, based on how long the participants spent sitting while working, in a vehicle, watching television, or lying down, except sleeping [11]. We measured PAL of participants twice during pregnancy which in T1 and T3 of pregnancy.

Out of 276, 93 were dropped out because of refuse to continue the study, moving out of the research 
location, pregnancy loss, lost contact and did not complete physical activity assessment.

\section{Birth size outcomes}

Gestational age at birth was calculated from the estimated gestational age examined by obstetricians or midwives performed using transabdominal ultrasound or date of last menstrual period in the absence of ultrasound at the Maternal Clinic or Hospital. The baby birth weight was documented in the birth record immediately after birth using a digital baby weight scale (Seca 385, Seca GmbH. Co. kg, Hamburg, Germany). The Baby's birth length and head circumference were measured to the nearest $1 \mathrm{ml}$ using a stadiometer and pita meter (OneMed-Medicom stature meter, YF.05.05.V.A.1022, Jakarta, Indonesia).

\section{Statistical analysis}

Data were analyzed using the IBM SPSS Statistics for Windows (version 23.0; SPSS, Inc., Chicago, IL, USA). Continuous variables with normal distribution were presented as mean \pm SD and nonnormal variables were presented as median (IQR). Categorical variables were presented as frequency and percentage. The normality of the distribution of outcome variables was tested by the Kolmogorov-Smirnov test.

Physical activity status was treated as categorical variables (presence or absence) among the women in the first and third trimesters. Chi-square and student's t-test were tested to assess the differentiation of the subject's maternal characteristic by maternal physical activity status during pregnancy. Analysis of the association between maternal PAL and birth size outcomes was evaluated by multivariable linear regression test and adjusting for confounding variables such as maternal age, energy intake, PP-BMI, and infant gender, while multivariable logistic regression was used to examine the association between PP-BMI and PAL. Two-sided $p<0.05$ was considered statistically significant.

\section{Results \\ Characteristics of the participants}

The characteristics of the VDPM cohort study participants are presented in Table 1. We categorized subject characteristics by maternal physical activity status during pregnancy (T1 and T3). We found that older age women were physically active than younger ages women in T1 pregnancy $(p=0.006)$. Maternal mean PP BMI was not significantly different between inactive and active women during pregnancy (T1 and T3 $p>0.05$ ). Moreover, from all the participants, $12.5 \%$ were underweight, while $55.2 \%, 19.8 \%$, and $12.50 \%$ were normal, overweight, and obese, respectively, according to the BMI classification.

In the present study, participants had a significant difference in PAL at T1 and T3 ( $p=0.045)$. The proportion of inactive women was higher in the third trimester compared to the first trimester. Women in the third trimester had 2.18 times higher to have a lower PAL (Table 2). $74.3 \%$ of women in T1 had inactive physical activity while $25.7 \%$ were active. Similarly, $77.1 \%$ of women in T3 were inactive while only $22.9 \%$ were active.

Table 2: Comparison of physical activity status during pregnancy $^{\mathrm{a}}$

\begin{tabular}{lllll}
\hline PAL at T1 & PAL at T3 & & OR $(95 \%$ Cl $)$ & p-value \\
\cline { 2 - 3 } & Inactive $(\mathrm{n}=141)$ & Active $(\mathrm{n}=42)$ & & \\
\hline Inactive $(\mathrm{n}=136)$ & $110(78.0)$ & $26(61.9)$ & $2.18(1.04-4.57)$ & 0.045 \\
Active $(\mathrm{n}=47)$ & $31(22.0)$ & $16(38.1)$ & & \\
\hline PAL $\mathrm{Ph})$ & & &
\end{tabular}

PAL: Physical activity levels, T1: First trimester, T3: Third trimester, OR: Odds ratio, Cl: Confidence interval. ${ }^{a}$ Data are expressed as number (percentage frequency) and tested by Chi-square.

The association between PP-BMI and physical activity with birth size outcomes

The association between PP-BMI status and physical activity status during pregnancy is presented in Table 3. There was no significant relationship between PP-BMI status and maternal physical activity during pregnancy $(p>0.05)$.

The association between PAL and birth size outcomes is shown in Table 4 . Women were physically active in T1 more likely to have a higher mean birth weight ( $p=0.032)$. However, no significant association was found in the birth length and head circumference ( $p>0.05$ ) among T1 and T3 pregnancy.

The association between PP-BMI and birth weight is shown in Figure 2a. PP-BMI was not significantly associated with birth weight $(p=0.074)$. However, group comparison showed that a significant difference in birth weight between women in underweight status and obese status was found $(p=0.025)$. Similarly, there was no association between PP-BMI with birth length (Figure $2 b$ ) and head circumference (Figure 2c). However, group

Table 1: Subject characteristics by maternal physical activity status in the first and third trimester ${ }^{\mathrm{a}}$

\begin{tabular}{|c|c|c|c|c|c|c|}
\hline \multirow[t]{2}{*}{ Parameters } & \multicolumn{3}{|l|}{ T1 } & \multicolumn{3}{|l|}{ T3 } \\
\hline & Inactive $(n=136)$ & Active $(n=47)$ & $p$-value ${ }^{b}$ & Inactive $(n=141)$ & Active $(n=42)$ & $p$-value ${ }^{b}$ \\
\hline Age (years) & $29.9 \pm 5.7$ & $31.5 \pm 4.9$ & 0.006 & $29.2 \pm 5.7$ & $30.9 \pm 5.1$ & 0.075 \\
\hline Monthly income (IDR in million) & $3.2 \pm 4.6$ & $2.8 \pm 2.0$ & 0.630 & $2.9 \pm 2.4$ & $3.7 \pm 7.3$ & 0.508 \\
\hline PP-BMI $\left(\mathrm{kg} / \mathrm{m}^{2}\right)$ & $23.4 \pm 4.5$ & $23.3 \pm 4.1$ & 0.873 & $23.5 \pm 4.5$ & $22.9 \pm 4.1$ & 0.414 \\
\hline $\operatorname{MUAC}(\mathrm{cm})$ & $27.0 \pm 3.8$ & $26.8 \pm 3.9$ & 0.753 & $27.9 \pm 3.8$ & $27.4 \pm 3.5$ & 0.526 \\
\hline Birth weight (g) & $3179.0 \pm 446.0$ & $3306.4 \pm 389.2$ & 0.083 & $3209.3 \pm 435.3$ & $3219.1 \pm 438.0$ & 0.902 \\
\hline Birth length $(\mathrm{cm})$ & $48.4 \pm 3.2$ & $49.1 \pm 1.8$ & 0.219 & $48.8 \pm 1.7$ & $48.6 \pm 2.6$ & 0.569 \\
\hline Head circumference $(\mathrm{cm})$ & $33.8 \pm 2.8$ & $34.3 \pm 1.6$ & 0.338 & $34.0 \pm 1.9$ & $33.9 \pm 1.8$ & 0.809 \\
\hline
\end{tabular}


Table 3: Association of prepregnancy BMI status and physical activity status during pregnancy

\begin{tabular}{|c|c|c|c|c|c|c|c|c|c|c|}
\hline \multirow[t]{2}{*}{ PP-BMI Status } & \multicolumn{5}{|c|}{ Physical Activity Status T1 n (\%) } & \multicolumn{5}{|c|}{ Physical Activity Status T3 n (\%) } \\
\hline & Inactive $(n=136)$ & Active $(n=47)$ & OR & $95 \% \mathrm{Cl}$ & p-value & Inactive $(n=141)$ & Active $(n=42)$ & OR & $95 \% \mathrm{Cl}$ & p-value \\
\hline Underweight $(n=22)$ & $17(12.5)$ & $5(10.6)$ & 1.00 & & 0.97 & $16(11.3)$ & $6(14.3)$ & 1.00 & & 0.69 \\
\hline Normal $(n=104)$ & $76(55.9)$ & $28(59.6)$ & 0.83 & $0.31-2.18$ & & 79 (55.3) & $26(61.9)$ & 0.80 & $0.28-2.31$ & \\
\hline Overweight $(n=36)$ & $27(19.8)$ & $9(19.2)$ & 0.80 & $0.26-2.45$ & & $30(21.3)$ & $6(14.3)$ & 0.41 & $0.11-1.56$ & \\
\hline Obese $(n=21)$ & $16(11.8)$ & $5(10.6)$ & 0.90 & $0.26-3.08$ & & $17(12.1)$ & $4(9.5)$ & 0.58 & $0.14-2.34$ & \\
\hline
\end{tabular}

Table 4: Association between physical activity and birth size outcomes

\begin{tabular}{|c|c|c|c|c|c|c|}
\hline \multirow[t]{2}{*}{ Physical activity status } & \multicolumn{2}{|l|}{ Birth weight $(\mathrm{g})$} & \multicolumn{2}{|c|}{ Birth length $(\mathrm{cm})$} & \multicolumn{2}{|c|}{ Head circumference $(\mathrm{cm})$} \\
\hline & Mean \pm SE & Mean difference $(95 \% \mathrm{Cl})$ & Mean \pm SE & Mean difference $(95 \% \mathrm{Cl})$ & Mean \pm SE & Mean difference $(95 \% \mathrm{Cl})$ \\
\hline \multicolumn{7}{|c|}{$x_{1}$} \\
\hline Inactive & $3171.9 \pm 35.7$ & Ref & $48.6 \pm 0.2$ & Ref & $33.8 \pm 0.2$ & Ref \\
\hline Active & $3327.2 \pm 61.4$ & $155.3(13.8-296.8)$ & $49.1 \pm 0.3$ & $0.4(-0.1-1.1)$ & $34.4 \pm 0.3$ & $0.4(-0.2-1.1)$ \\
\hline p-value ${ }^{a}$ & 0.032 & & 0.16 & & 0.16 & \\
\hline p-interaction ${ }^{b}$ & 0.001 & & 0.14 & & 0.30 & \\
\hline \multicolumn{7}{|l|}{ T3 } \\
\hline Inactive & $3204.3 \pm 35.3$ & Ref & $48.8 \pm 0.2$ & Ref & $34.0 \pm 0.2$ & Ref \\
\hline Active & $3236.9 \pm 65.2$ & $32.6(-114.5-179.7)$ & $48.6 \pm 0.3$ & $-0.2(-0.8-0.5)$ & $34.0 \pm 0.3$ & $0.054(-0.60-0.71)$ \\
\hline$p$-value ${ }^{a}$ & 0.67 & & 0.65 & & 0.87 & \\
\hline p-interaction ${ }^{b}$ & 0.011 & & 0.28 & & 0.034 & \\
\hline
\end{tabular}

comparison showed that obese women had significantly bigger birth head circumference compared to normal $(p=0.047)$ and overweight $(p=0.038)$.

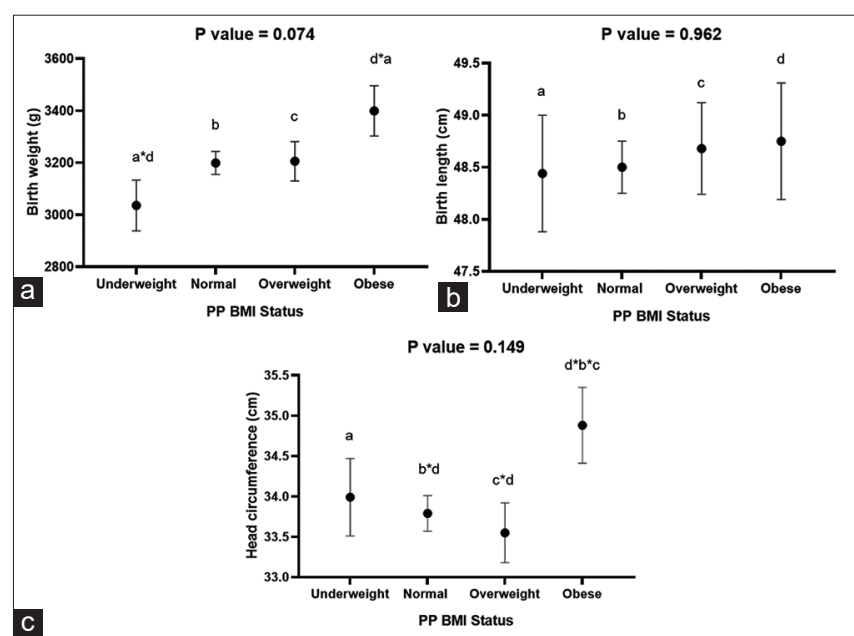

Figure 2: The association between prepregnancy body mass index and (a) birth weight, (b) birth length, and (c) head circumference

Moreover, we tested whether PP BMI affects maternal PAL and birth size outcomes. An interaction was found between PAL at T1 and PP-BMl on birth weight (p-interaction $=0.001)$ (Figure 3 and Table 4$)$. In the T3 of pregnancy, we found an interaction between PAL and PP-BMI on birth weight and head circumference outcomes (p-interaction $=0.011$ and 0.034 , respectively). The T3 of pregnant women who are physically active had a significantly higher birth weight when they were underweight $(p=0.029)$ (Figure 4).

\section{Discussion}

Women who have regular physical activity have several health benefits during pregnancy including

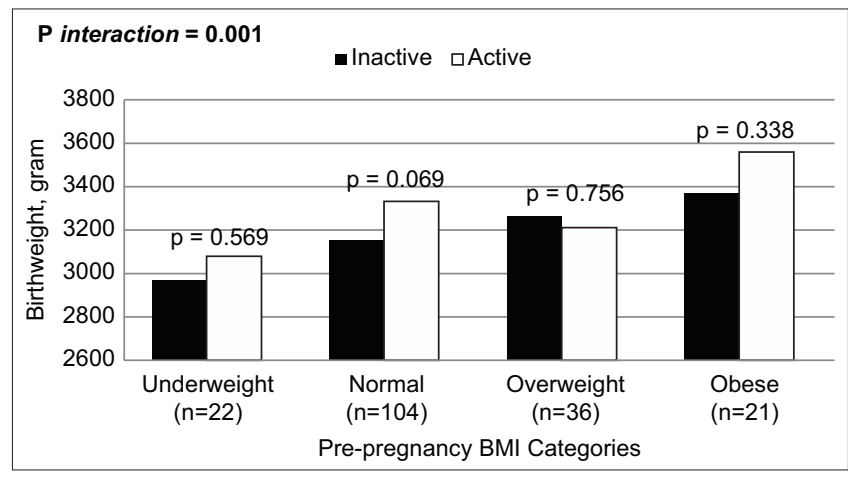

Figure 3: The association between physical activity status at T1 and birth weight based on pre-pregnancy body mass index categories

reduced risk of excess weight and complication related to pregnancy outcomes such as gestational diabetes, preterm birth, and pre-eclampsia [7]. In this VDPM cohort study, we measured the association between physical activity during pregnancy and birth size outcomes (birth weight, birth length, and head circumference). We also measured other determinants of confounding variables such as PP-BMI and GWG during pregnancy that may affect birth size outcomes. Our findings highlighted some points; (1) Maternal PAL during pregnancy had a significant difference between T1 and T3 of pregnancy, (2) maternal physical activity during pregnancy had no association with birth size

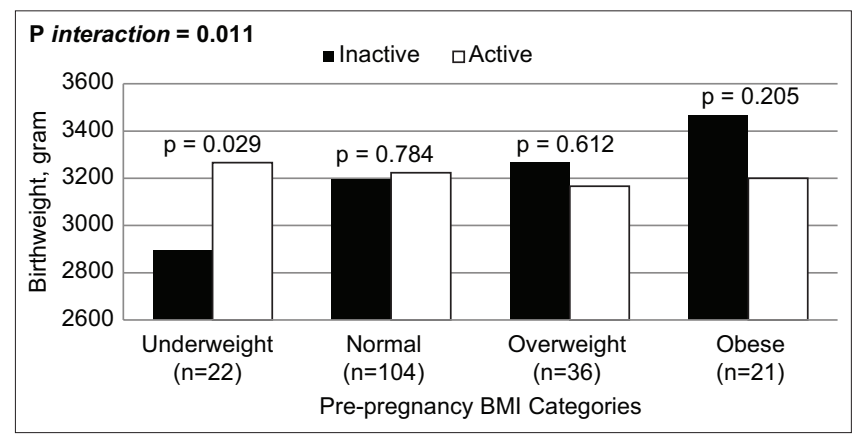

Figure 4: The association between physical activity status at T3 and birth weight based on prepregnancy body mass index categories 
outcomes in the unadjusted model, (3) there is an association between first trimester's PAL and birth weight after adjustments with confounding factors such as maternal age, PP-BMI, energy intake, infant gender, and GWG, (4) there is no significant association of PAL with other variables, such as PP-BMI, birth length, and head circumference, and (5) there is an interaction between PAL and PP BMI on birth weight and head circumference.

Recent cohort studies found that physical activity during pregnancy, either active or inactive, was not associated with adverse birth outcomes [12], [13]. However, several studies revealed an association when measuring PAL in various levels and specific activities with low birth weight and preterm birth [14], [15], [16]. Furthermore, a systematic review found that the risk of preeclampsia might be reduced by regular PAL during pregnancy [15]. Those studies showed that PAL may have benefits for fetal development. Meanwhile, in the present study, we had a higher inactive physically participants in the third trimester. The decreasing PAL during pregnancy generally started in the first trimester when the vomiting, profound fatigue, and nausea happened and the physical limitations of the third trimester begin [17].

The implication of physical activity in early pregnancy had a significant association to improve placental function in healthy pregnancy although it showed different results and remains unclear about its impacts on fetal growth in women with pregnancy complications [18]. The effect of maternal physical activity on fetal growth remains debatable on endothelial dysfunction and abnormal perfusion which is leading to preterm birth [12]. The benefit of exercise not only improving vascularity of energy supply by fulfilling fetal nutrient needs but also creates a sense of comfort during pregnancy and increasing the quality of life of the pregnant women which will certainly have a good impact on fetal growth [19]. However, excessive PAL may reduce maternal blood flow to the placenta to cover inactive tissue requirement (adipose tissue) and due to physiologic stress of exercise [20], [21].

Other variables that would modulate the association between PAL and birth size outcomes include infant's gender, GWG, and maternal BMI before pregnancy [22]. A study in rural Malawi that determined PP-BMI and maternal GWG showed a positive association with birth weight and head circumference. Compared to normal-weight women, underweight women were more likely to have a higher risk of stunted infants [23]. Another prospective study, the Black Women's Health Study, reported that women with $<18 \mathrm{~kg} / \mathrm{m}^{2}$ were more likely to have a higher risk of spontaneous preterm birth compared to normal and obese women [24]. The Norwegian Mother and Child Cohort Study revealed that newborn birth weight increased with both increasing maternal PP-BMI and maternal weight gain during pregnancy in all categories of maternal PP-BMI [25]. This study observed a significantly lower birth weight in underweight women compared to obese women. The relationship between PP-BMI and fetal growth is biologically plausible, although the direct affecting pathway from PP-BMI to the birth size outcomes is not known. A plausible explanation is that there is a complex interaction between genetics, maternal nutrition, GWG, and other factors that were mediated through the maternal nutrition pathway [26]. Hereafter, more research with a larger sample size is needed to determine the association between PP-BMI and birth size outcomes in Indonesian population.

In the present study, several limitations should be acknowledged. First, the sample size was relatively modest and therefore suggesting that our sample might not be the representative of women in West Sumatra, let alone Indonesia. Second, the variables of PP-BMI and physical activity may lead method bias data. PP-BMI was self-reported and collected through the information from maternal and child book records. While GPAQ was selected to determine the physical activity status among pregnant mothers, the results appear to overestimate physical activity and underestimate SB during pregnancy [27]. Therefore, there is a high susceptibility for participants to both recall bias and misreporting. Third, we used BMI, a proxy for body composition, rather than using more methods that are more accurate to assess body composition such as percentage body fat, muscle mass, and fat mass. The strength of this study was a prospective cohort study and highly trained study staff which were recruited to perform study protocols. Finally, based on our knowledge, our study is the first study that identifies the relationship between PAL status and PP-BMI on birth size outcomes in Indonesian pregnant women.

\section{Conclusion}

Our study provides evidence that maternal physical activity status was associated with newborn birth weight. Pregnant women who have underweight status before the pregnancy and are physically active at T3 were apparently to have heavier birth weight. Future research is needed, in particular, focusing on intervention studies or randomized controlled trials to confirm the impact of PALs on maintaining maternal health and prevent adverse pregnancy outcomes.

\section{Acknowledgments}

The authors are grateful for the help and teamwork of the research team and healthcare provider 
in the field, such as midwives, doctors, and all staff from the public health community centers in each district. A.S.A. thanks to the Ministry of Research, Technology and Higher Education (Menristekdikti) of Indonesia for the PKPI scholarship program and Dr. Vimal Karani for the guidance during PKPI scholarship program in the Department of Food and Nutrition Science, University of Reading, England, UK. We appreciate all the hard work from our research team, enumerators, cadres, phlebotomists, and supervisors.

\section{Disclaimers}

The views expressed in the submitted article are his or her own and not an official position of the institution or funder.

\section{Source's Support}

This research was supported by the Ministry of Research, Technology and Higher Education of the Republic of Indonesia (Menristekdikti) with project name The Research of Master Program Leading to Doctoral Degree for Excellent Students (PMDSU Batch-2) in the year of 2018 (Grant No: 050/SP2HL/LT/DRPM/2018) and Indonesian Danone Institute Foundation (Grant No: 007/ROG-D/IDIF/X2016). The views expressed herein are those of the individual authors and do not necessarily reflect those of the Indonesian Danone Institute Foundation (IDIF).

\section{Author Contribution}

A.S.A.; writing - first manuscript, A.S.A.; analyzed data and conducted sample collection, $Y Y$, N.I.L. and S.G.M.; conceiving and supervising, C.K and A.S.A; finalizing, revising, editing, formatting, and submitting the manuscript. All authors have read and agreed to the published version of the manuscript.

\section{References}

1. Smith KM, Campbell CG. Physical activity during pregnancy: Impact of applying different physical activity guidelines. J Pregnancy. 2013;2013:165617. https://doi. org/10.1155/2013/165617
2. Nascimento SL, Surita FG, Godoy AC, Kasawara KT, Morais SS. Physical activity patterns and factors related to exercise during pregnancy: A cross sectional study. PLoS One. 2015;10(7):e0133564. https://doi.org/10.1371/journal. pone.0133564

PMid:26083416

3. Aji AS, Desmawati D, Yerizel E, Lipoeto NI. The association between lifestyle and maternal vitamin $D$ during pregnancy in West Sumatra, Indonesia. Asia Pac J Clin Nutr. 2018;27(6):1286. PMid:30485928

4. Roland MC, Friis CM, Godang K, Bollerslev J, Haugen G, Henriksen T. Maternal factors associated with fetal growth and birthweight are independent determinants of placental weight and exhibit differential effects by fetal sex. PLoS One. 2014;9:e87303. https://doi.org/10.1371/journal.pone.0087303

5. Ferraro ZM, Gaudet L, Adamo KB. The potential impact of physical activity during pregnancy on maternal and neonatal outcomes. Obstet Gynecol Surv. 2012;67(2):99-110. https://doi. org/10.1097/ogx.0b013e318242030e

PMid:22325300

6. Muktabhant B, Lumbiganon P, Ngamjarus C, Dowswell T. Interventions for preventing excessive weight gain during pregnancy. Cochrane Database Syst Rev. 2012;4:CD007145. https://doi.org/10.1002/14651858.cd007145.pub2

PMid:22513947

7. Tremblay MS, Shields M, Laviolette M, Craig CL, Janssen I, Connor Gorber S. Fitness of Canadian children and youth: Results from the 2007-2009 Canadian health measures survey. Health Rep. 2010;21(1):7-20.

PMid:20426223

8. Aji AS, Erwinda E, Yusrawati Y, Malik SG, Lipoeto NI. Vitamin D deficiency status and its related risk factors during early pregnancy: A cross-sectional study of pregnant Minangkabau women, Indonesia. BMC Pregnancy Childbirth. 2019;19(1):183. https://doi.org/10.1186/s12884-019-2341-4

PMid:31117971

9. Aji AS, Yerizel E, Desmawati D, Lipoeto NI. Low materna Vitamin $D$ and calcium food intake during pregnancy associated with place of residence: A cross-sectional study in West sumatran women, Indonesia. Open Access Maced J Med Sci. 2019;7(17):2879-85. https://doi.org/10.3889/oamjms.2019.659 PMid:31844453

10. Lim JU, Lee JH, Kim JS, Hwang YI, Kim TH, Lim SY, et al Comparison of World Health Organization and Asia-Pacific body mass index classifications in COPD patients. Int J Chron Obstruct Pulmon Dis. 2017;12:2465-75. https://doi.org/10.2147/ copd.s141295

PMid:28860741

11. Sattler MC, Jaunig J, Watson ED, van Poppel MN, Mokkink LB, Terwee CB, et al. Physical activity questionnaires for pregnancy: A systematic review of measurement properties. Sports Med. 2018;48(10):2317-46. https://doi.org/10.1007/ s40279-018-0961-x PMid:30094797

12. Bisson M, Croteau J, Guinhouya BC, Bujold E, Audibert F, Fraser WD, et al. Physical activity during pregnancy and infant's birth weight: Results from the 3D birth cohort. BMJ Open Sport Exerc Med. 2017;3(1):e000242. https://doi.org/10.1136/ bmjsem-2017-000242 PMid:28761717

13. Rêgo AS, Batista RF, Ribeiro CC, Bettiol H, Cardoso VC, Barbieri MA, et al. Physical activity in pregnancy and adverse birth outcomes. Cad Saúde Pública. 2016;32(11):e00086915 PMid:27925023

14. Xi C, Luo M, Wang T, Wang Y, Wang S, Guo L, et al. Association 
between maternal lifestyle factors and low birth weight in preterm and term births: A case-control study. Reprod Health. 2020;17(1):93. https://doi.org/10.1186/s12978-020-00932-9

PMid:32527333

15. Kasawara KT, do Nascimento SL, Costa ML, Surita FG, Silva JL. Exercise and physical activity in the prevention of pre-eclampsia: Systematic review. Acta Obstet Gynecol Scand. 2012;91(10):1147-57. https://doi. org/10.1111/j.1600-0412.2012.01483.x PMid:22708966

16. Vamos CA, Flory S, Sun H, DeBate R, Bleck J, Thompson E, et al. Do physical activity patterns across the Lifecourse impact birth outcomes? Matern Child Health J. 2015;19(8):1775-82. https://doi.org/10.1007/s10995-015-1691-4 PMid:25874877

17. Evenson $K R$, Barakat $R$, Brown WJ, Dargent-Molina $P$, Haruna M, Mikkelsen EM, et al. Guidelines for physical activity during pregnancy: Comparisons from around the world. Am J Lifestyle Med. 2014;8(2):102-21. https://doi. org/10.1177/1559827613498204 PMid:25346651

18. Bauer I, Hartkopf J, Kullmann S, Schleger F, Hallschmid M, Pauluschke-Fröhlich J, et al. Spotlight on the fetus: How physical activity during pregnancy influences fetal health: A narrative review. BMJ Open Sport Exerc Med. 2020;6(1):e000658. https:// doi.org/10.1136/bmjsem-2019-000658 PMid:32206341

19. Bahadoran P, Mohamadirizi S. Relationship between physical activity and quality of life in pregnant women. Iran J Nurs Midwifery. 2015;20:282.

20. Pathirathna ML, Sekijima K, Sadakata M, Fujiwara N Muramatsu Y, Wimalasiri KM. Effects of physical activity during pregnancy on neonatal birth weight. Sci Rep. 2019;9:6000. https://doi.org/10.1038/s41598-019-42473-7

21. Newton ER, May L. Adaptation of maternal-fetal physiology to exercise in pregnancy: The basis of guidelines for physical activity in pregnancy. Clin Med Insights Womens

Health. 2017;10:1179562X17693224. https://doi.
org/10.1177/1179562×17693224

PMid:28579865

22. Badon SE, Wander PL, Qiu C, Miller RS, Williams MA Enquobahrie DA. Maternal leisure time physical activity and infant birth size. Epidemiology. 2016;27(1):74-81. https://doi. org/10.1097/ede.0000000000000399

PMid:26427724

23. Gondwe A, Ashorn P, Ashorn U, Dewey KG, Maleta K, Nkhoma $\mathrm{M}$, et al. Pre-pregnancy body mass index (BMI) and maternal gestational weight gain are positively associated with birth outcomes in rural Malawi. PLoS One. 2018;13:e0206035. https://doi.org/10.1371/journal.pone.0206035 PMid:30352100

24. Wise LA, Palmer JR, Heffner LJ, Rosenberg L. Prepregnancy body size, gestational weight gain, and risk of preterm birth in African-American women. Epidemiology. 2010;21(2):243-52. https://doi.org/10.1097/ede.0b013e3181cb61a9 PMid:20124904

25. Stamnes Koepp UM, Frost Andersen L, Dahl-Joergensen K, Stigum H, Nass O, Nystad W. Maternal pre-pregnant body mass index, maternal weight change and offspring birthweight. Acta Obstet Gynecol Scand. 2012;91:243-9. https://doi. org/10.1111/j.1600-0412.2011.01321.x

PMid:22077818

26. Hinkle SN, Schieve LA, Stein AD, Swan DW, Ramakrishnan U, Sharma AJ. Associations between maternal prepregnancy body mass index and child neurodevelopment at 2 years of age. Int J Obes (Lond) 2012;36(10):1312-9. https://doi.org/10.1038/ ijo.2012.143

PMid:22964791

27. Watson ED, Micklesfield LK, van Poppel MN, Norris SA, Sattler MC, Dietz P, et al. Validity and responsiveness of the global physical activity questionnaire (GPAQ) in assessing physical activity during pregnancy. PLoS One. 2017;12(5):e0177996. https://doi.org/10.1371/journal.pone.0177996

PMid:28552977 